\title{
Tres apuntes sobre la filosofía neoplatónica de la luz en la Canción al nacimiento de la hija del marqués de Alcañices, de fray Luis de León
}

Three Notes about Neoplatonic Philosophy of Light in Fray Luis de Leon's Canción al nacimiento de la hija del marqués de Alcañices

\section{GINÉs TORRES SALINAS}

Departamento de Literatura Española

Universidad de Granada

Facultad de Filosofía y Letras

Edificio A, campus de Cartuja. Granada, 18071

ginestorres@ugr.es

Orcid ID: 0000-0003-3376-8908

Resumen: El poema que fray Luis de León dedica a la hija del marqués de Alcañices se suele entender como un poema menor, de circunstancias, comparado con los poemas mayores de su producción. Un estudio del mismo a partir de determinados parámetros de la "poética de la luz" propia del neoplatonismo ficiniano -la cristianización de ciertos motivos paganos, como Apolo; la influencia de ciertos planetas; la relación entre cuerpo y almapone de relieve que la composición, lejos de ser un "divertimento", reproduce la misma lógica interna que sostiene sus composiciones mayores, pues guarda profunda relación con la doctrina neoplatónica difundida por todo el Renacimiento europeo.

Palabras clave: Fray Luis de León. Astrología. Neoplatonismo. Ficino. Alcañices.
RECIBIDO: 31 DE JULIO DE 2016 ACEPTADO: 17 DE OCTUBRE DE 2016 
E 111 de enero de 1569 nacía doña Tomasina de Borja, hija de Álvaro de Borja y Elvira Enríquez, marqueses de Alcañices. A la niña dedicó fray Luis de León su "Canción al nacimiento de la hija del marqués de Alcañices" (2006, 27-32), una composición adscrita al genethliacon (Rico 1981, 247; Alcina 85), género de carácter eminentemente natalicio y celebratorio, a manera de horóscopo, en especial si son ilustres los recién nacidos. En parte por este carácter cercano al poema de circunstancias y en parte porque no pertenece al núcleo de las grandes composiciones líricas de fray Luis -la oda $A$ Francisco de Salinas, la Noche serena y la oda $A$ la vida retirada-, el poema no ha sido demasiado bien ponderado por la crítica, que lo ha considerado como un poema menor o poco valioso, un ejercicio formal devenido casi en juego, por lo que vendría a ocupar un lugar accidental dentro de su obra (Prieto 319; en cierto modo Asensio 101; Alarcos Llorach 137).

Sin embargo, más allá de las exigencias impuestas por el género, el descenso del alma de la niña desde los espacios celestiales hasta su cuerpo de recién nacida responde a algunos de los aspectos centrales del neoplatonismo renacentista, especialmente a aquellos situados en la órbita de lo que en otra ocasión hemos llamado la poética renacentista de la luz (Torres Salinas 2013, 96). ${ }^{1}$ Una lectura atenta hacia esas cuestiones pone de relieve hasta qué punto la Canción a la hija del marqués de Alcañices trasciende la categoría de poema de circunstancias para constituir una de las más interesantes manifestaciones de la influencia de la filosofía neoplatónica en la poesía española del Renacimiento.

II

El poema es una interesante muestra del uso que el neoplatonismo renacentista hace del rico trasfondo pagano propio del periodo. Aunque Oreste Ma-

1. Huelga decir que la cuestión de la poética de la luz implica una densísima tradición teológica que, por razones de espacio, no podemos aquí ni siquiera esbozar. Baste señalar aquí, acaso como punto de partida, los rasgos que Mancho Duque atribuye a la significación metafórica de la luz, referidos a san Juan de la Cruz (137): " $1 .^{\circ}$ ) actividad de carácter intelectivo, de origen racionalnatural, que permite el conocimiento de fenómenos naturales y, $2^{\circ}$ ) actividad de carácter intelectivo de orden suprarracional o sobrenatural que permite el conocimiento de verdades naturales o sobrenaturales". En este sentido, los trabajos sobre san Juan de la Cruz han supuesto interesantes aportaciones al tema, como se puede ver en Fernández Leborans (1973; 1977, 99-144; 1978, 223-31), Thompson (203-04), Ynduráin (51-83), García Palacios (1991, 1992), Rodríguez (70-76; 184-93) o Lara Garrido (120-67), este último en su estudio sobre la poesía de Francisco de Aldana. Asimismo, una buena síntesis del problema en san Juan la encontramos en las páginas 634-36 de la edición de su poesía completa a cargo de Paola Elia y María Jesús Mancho. 
crì ve "clara la lucha del poeta contra el macizo bloque del propio aparato mitológico-pagano" (51), no parece que se trate tanto de una lucha como de un intento por parte de fray Luis de adaptar -sin demasiada dificultad, por cierto- al molde cristiano "el aparato neoplatónico y mitológico del descensus del alma a través de los diversos planetas" (51), en "un marco zodiacal de estirpe neolatina" (Pérez-Abadín 495).

La oda comienza con una comparación entre el brillo de la niña y el del Sol: "Hermoso sol luciente, / que el día das y llevas [...] / sal, y verás nacido tu traslado" (vv. 6-10). Tanto es el poder luminoso de doña Tomasina que el Sol podría quedarse en la oscuridad en que mora en el momento del nacimiento de la niña, las once de la noche (Cuevas 101), porque "con la luz nacida / podrá ser nuestra esfera esclarecida" (vv. 14-15). No es casual la advocación solar en el marco del neoplatonismo renacentista, pues como bien ha estudiado Garin en ese contexto aparece un "eliocentrismo «ideale», metafísico y teológico" (1975, 23), un "mito solar" (1981b, 292), que se difunde por todo el campo cultural e ideológico. El Sol se convierte poco a poco en el centro del universo, no tanto todavía en el sentido cosmológico propio de la revolución copernicana -que, por cierto, beberá con especial interés de las fuentes neoplatónicas-, ${ }^{2}$ sino como "lugar de expresión máxima" del alma del mundo (Rodríguez 222), punto en que reside la vida y desde el cual se transmite al resto del universo gracias a sus rayos luminosos.

La tratadística del periodo está llena de ejemplos al respecto. En la traducción del Corpus Hermeticum que Marsilio Ficino completó en 1463, y que desde muy pronto conoció cierta difusión en Castilla, ${ }^{3}$ se lee:

pues el sol ilumina a las demás estrellas no tanto por la potencia de su luz como por su divinidad y santidad. En verdad, Asclepio, debes creer en el sol como segundo dios, el que gobierna y alumbra a todos los seres vivos terrestres, animados o inanimados [...]. Si el cosmos es eterno, entonces el mismo sol lo es; eterno gobernador de las fuentes de la vida y de toda vivacidad, a las que asiste con asiduidad. Dios gobierna, pues, eternamente a los seres vivos y vivificantes que existen en el mundo y provee eternamente de la vida misma. (Textos Herméticos 473-74)

El propio Marsilio Ficino, casi treinta años después, en 1492, trabaja en un tratado de nombre De Sole. En su tercer capítulo escribe que "el Sol, como

2. Ver Garin (1975) y Vasoli (1977, 313-50).

3. Ver Béhar (2010). 
manifiesto señor del cielo, regula y guía todas las cosas celestes", ${ }^{4}$ recuperando así la idea de estirpe neoplatónica, según la cual este es "la estatua visible de Dios, colocada por Dios mismo en este templo del mundo, para que desde cualquier parte todos lo admiren sobre todas las cosas". ${ }^{5}$ Incluso los astrónomos adoptarán en parte este lenguaje: “¿Quién en este bellísimo templo pondría esta lámpara en otro lugar mejor, desde el que pudiera iluminar todo. Y no sin razón unos le llaman lámpara del mundo, otros mente, otros rector?", dirá Copérnico (34); "él es el único que comunica y difunde la virtud vital", escribirá Giordano Bruno (80); “en verdad, el Sol está en el centro del mundo, es el corazón del mundo, la fuente de la luz, la fuente del calor, el origen de la vida y del movimiento mundanal”, añadirá Kepler (185).

Así, si doña Tomasina eclipsa al Sol es porque la luminosidad de su alma, de nuevo desde una perspectiva propia del neoplatonismo, es luminosa en exceso, como corresponde, lo veremos, tanto a su familia como a su propia bondad. Nos encontramos en una suerte de paralelo de la figura de la Dama Sol, que tanta presencia tiene en la poesía amorosa del periodo. De filiación petrarquesca (Lara Garrido 54-55), la imagen otorga a la figura de la dama, en este caso la niña, una superlativa capacidad lumínica, que provoca su identificación con el Sol, en tanto que ambos concentran en sí la luz y la irradian a todo el mundo, otorgándole sus virtudes benéficas y fecundadoras, merced a una bondad y perfección del alma que de tan luminosa -naturaleza de la que nos ocuparemos en el epígrafe correspondiente- acaba por superar al propio Sol. ${ }^{6}$

Tras la advocación solar, fray Luis relata el descenso del alma de la niña, desde la más alta de las esferas hasta el cuerpo recién nacido. Se trata de una imagen de amplio recorrido en la tradición neoplatónica, desde la metáfora de los "ríos planetarios" recogida por Marciano Capella en Las bodas de Filología y Mercurio (Flórez Miguel 363-64) hasta el propio Marsilio Ficino, quien se

4. Hemos decidido, para facilitar la lectura, ensayar una traducción en aquellos casos en que no exista versión del texto de Ficino en español. Adjuntamos, en cada caso, la versión en latín, según la edición de las obras completas de 1576 (que puede consultarse en la Biblioteca Virtuale OnLine dil Istituto Nazionale di Studi sul Rinascimento de la Scola Normale Superiore di Pisa); así como la de la traducción más fiable: "Sol tanquam manifestus coeli Dominus omnia prorsus coelestia regit, et moderatur" $(1962,966)$; "Il Sole, quale un manifesto signore del cielo, regola e guida tutte le cose celesti" (1952b, 975).

5. "Arbitratus quoque est Solem esse perspicuam Dei statuam in hoc templo mundano, ab ipso Deo positam, intuentibus undique prae caeteris admirandam" $(1962,970)$; "il Sole fosse la statua visibile di Dio posta da Dio medesimo in questo tempio del mondo perché da ogni parte tutti la ammirassero sopra tutto" (1952b, 991).

6. Para un análisis en detalle de la cuestión de la Dama Sol, ver García (139-55) y Torres Salinas (2015). 
refería en el De vita a la influencia que los astros podían ejercer sobre el alma en el momento de su bajada al cuerpo, admitiendo "lo que cuentan algunos filósofos de la naturaleza y algunos astrónomos, a saber, que el alma dotada de entendimiento desciende al feto humano en el mes del Sol, es decir, en el cuarto" $(2006,161)$. El poeta diseña así a lo largo de la oda un recorrido de clara huella ficiniana (Asensio 100-01), a través de la influencia de determinados astros, beneficiosos para la salud espiritual de la niña.

Nos interesa ahora centrarnos en el guía que tutela a doña Tomasina durante todo el descenso, "el rojo y crespo Apolo" (v. 31), trasunto del Sol, "que tus pasos guiando descendía / contigo al bajo polo" (vv. 32-33).? La figura de Apolo abre el poema a interesantes posibilidades interpretativas, sobre todo si atendemos a los esfuerzos del neoplatonismo, especialmente el ficiniano, por conseguir una armonía doctrinal entre la religión cristiana y la sabiduría antigua, especialmente platónica (Garin 1981b, 175; Saitta 8). Lo podemos comprobar en otro pasaje del De Sole. En el capítulo IX del tratado, Ficino trae a colación al Apolo que "con las saetas de sus rayos traspasa, purifica, licúa y eleva la masa de Pitón”, justo antes de referirse a la figura de Cristo:

No podemos olvidar que, del mismo modo en que esperamos que Cristo, en su reino, resucite con el esplendor de su cuerpo los cuerpos humanos de la tierra, esperamos cada año después del letal invierno al Sol, señor de Aries, llamando hacia la vida y la belleza tanto a las semillas de todas las cosas, escondidas como muertas bajo la tierra, como a los animales semivivos. ${ }^{8}$

7. Pérez-Abadín (496-97) ha visto en la figura la incorporación al poema, debidamente pasado por el filtro del platonismo cristiano, del motivo pagano del Genius - funo, para las mujeres-, divinidad tutelar encargada de proteger a la persona y velar por ella y posteriormente asimilada por el cristianismo a la figura de los santos patronos (Walker 47). Es interesante, en este sentido, el pasaje de la segunda égloga de Garcilaso (220-307; vv. 1271-88), donde el poeta canta al nacimiento del tercer duque de Alba, Fernando Álvarez de Toledo, en términos astrológicos muy similares a los de fray Luis con doña Tomasina, solo que aquí acompañado de Mercurio y Marte, dioses de la sabiduría y la guerra, propios de un niño y, en la época, no recomendables para una niña, motivos por los cuales (Vicente 316) no acompañan, como veremos, a doña Tomasina en su descenso.

8. "Hinc Apollo radiorum aculeis Pythoneam molem transfigit, purgat, dissolvit, attollit. Neque vero praetermittere fas est, quod quemadmodum speramus Christum tandem in suo regno venturum, et splendore sui corporis exundante humana a terra corpora prorsus suscitaturum, ita post hyemem letalem quotannis expectamus Solem in Ariete regnatem, semina rerum in terris quasi iam mortua et animalia semiviva ad vitam et pulchritudinem statim revocaturum" (1962, 971); "Per questo Apollo con le saette dei suoi raggi trapassa, purifica, discioglie, solleva la massa di Pitone. Né dobbiamo dimenticar che a quel modo in cui speriamo in Cristo finalmente reg- 
No es casual que Cristo y Apolo aparezcan aquí casi como solapados, pues su identificación será uno de los caminos que tomará el neoplatonismo renacentista en su intento de conciliar la sabiduría antigua con el cristianismo, gracias a la ductilidad proteica que abre su simbolismo.

El esfuerzo por encontrar conexiones entre ambas figuras llega a interesantes resultados. La escritura y publicación del De vita Libri Tres ${ }^{9}$ supuso para Marsilio Ficino no pocas preocupaciones, especialmente por su tercera parte, De vita caelitus comparanda, suerte de tratado de astrología redactado bajo los principios de la magia natural. En él recoge la vieja idea de Apolo como deidad tutelar de los médicos, como primer médico, de hecho, en la línea de la indagación pagana propia del Renacimiento. Sin embargo, consciente de que la temática del tratado podría conllevar posibles acusaciones de herejía o nigromancia, Ficino compuso una Apología en la que delimitaba con precisión la diferencia entre la magia natural, guía para los médicos, y la magia maligna y demoniaca, perturbadora de la salud de cuerpo y alma. Es ahí donde encontramos una imagen de Cristo directamente emparentada con el Apolo precursor de la medicina: "Y Cristo mismo, dador de vida, que dio mandato a sus discípulos de curar a los débiles por todo el mundo, ordenará a los sacerdotes que, si no pueden sanar con las palabras, tal y como hicieron sus discípulos, sanen al menos con las hierbas y las piedras". ${ }^{10}$ La relación entre Cristo y Apolo abre otra posibilidad, más importante para nosotros, al imaginario neoplatónico, gracias al carácter solar de la divinidad. El engarce no era difícil porque la identificación solar de Cristo estaba bien arraigada, como bien señalara Panofsky $(1975,220)$, en la prefiguración crística que, al modo magistralmente explicado por Auerbach (152), se lee en Malaquías 3, 20: "En cambio para vosotros, los que respetáis mi nombre, brillará el sol de justicia con la salvación en sus rayos". No es casual la identificación que hace el neoplatonismo entre Cristo y el Sol, pues tiene una profunda base ontológica y meta-

nante, che con lo splendore del suo corpo cusciterà dalla terra i corpi umani, analogamente aspettiamo ogni anno dopo l'inverno letale il Sole signore dell'Ariete, che richiama alla vita e alla belleza i semi delle cose, nascosti come morti nella terra, e gli animali semivivi" (1952b, 995).

9. Se trata, en realidad, de tres libros distintos, que, si bien tienen un profundo carácter unitario, fueron publicados con un intervalo de nueve años entre el primero (De vita sana, 1480) y los otros dos (De vita longa y De vita caelitus comparanda, 1489).

10. "Et Christus ipse, vitae largitor, qui discipulis mandavit languentes toto orbe curare, sacerdotibus quoque praecipiet, si minus verbis, ut illi quondam, mederi possint, saltem herbis et lapidibus medeantur" (1962, 376); "e Cristo stesso, largitore di vita, che diede mandato ai discepoli di curare $\mathrm{i}$ languenti in tutto il mondo, comanderà anche ai sacerdote che, se non possono sanare con le parole come quie suoi antichi discepoli, risanino almeno con le erbe e le pietre" $(1991,433)$. 
física, construida en torno a una noción común a ambos, la de la llamada medietas. Del mismo modo que, debido a que "el inmenso esplendor del Sol no procede del Sol, sino de Dios a través del Sol, y es luz que se manifiesta a los ojos, pero no es propia de ese globo solar, sino de Dios mismo", ${ }^{11}$ el Sol adquiere un rol de mediación vivificadora entre la divinidad y su creación, perfectamente análoga a la que supone Cristo $^{12}$ para la creación, en tanto que Dios hecho hombre. El nudo entre Cristo, el Sol y Apolo es entendida así por el neoplatonismo renacentista como una oportunidad tan difícil de desaprovechar como coherente y rentable para su sistema ontológico.

No podrá ser ajeno fray Luis a estas relaciones crístico solares, tan difundidas por todo el periodo. Sobre todo si tenemos en cuenta su dimensión de fraile de la orden agustina, cuya tradición filosófica dará tanta importancia al símbolo de la luz. Maristany (353) y Ramajo (22) han apuntado cómo fray Luis tuvo el comentario de san Agustín al Génesis-De Genesi ad litteram-como modelo para su curso universitario In Genesim. Allí, san Agustín habla de un "conocimiento matinal" de las cosas del mundo: "Conociéndolas en Dios con conocimiento matinal fue como la mañana, y conociéndolas en ellas mismas fue como la tarde" (675). Idea que trasluce en un pasaje de su Expositio in Genesim:

Y ciertamente no carece de misterio el que la primera voz de Dios y el primer mandato se hubieran empleado en el hacerse de la luz, pues por ello entendemos que todas las obras divinas se desarrollan en la luz, o más bien que es la luz la manifestación de la verdad, ajena de todo engaño y falacias, por lo que se dice que Dios es el Padre de las luces en Jac. 1: "toda dádiva buena y todo don perfecto desciende de arriba del Padre de las luces, en el cual no existe vaivén ni oscurecimiento, efecto de la variación, porque todo lo que de Él procede es luz". ${ }^{13}$

11. "Splendorem tantum in Sole patentem, non ex ipso quidem, sed ex Deo per ipsum ad cuncta procedere, tanquam non globi illius, sed Dei ipsius lumen, ita iam oculis manifestum" (1962, 972); "questo immenso splendore del Sole non procede dal Sole, ma da Dio attraverso il Sole, ed è luce che si manifesta agli occhi, ma non è propria di quel globo solare, bensì di Dio stesso" (1952b, 999).

12. Ver Kristeller $(1988,118-19)$, quien apunta con tino que dicha concepción se entienda de forma paralela a la del alma como entidad mediadora entre Dios y los hombres, cristalizando en el Discurso de Pico della Mirandola; Vasoli, quien habla de "mediazione cosmica e redentrice del Cristo-Verbo, rigeneratore del mondo e sull'intima partecipazione umana alla -deificatio" $(1999,47) ;$ y Lauster: "With the participation of the Son in the creation as an ideal prototype Ficino introduces the theory of Christ mediating the creation" (55).

13. En Maristany (353-54). 
La luminosidad solar quedará patente en la imagen del propio fundador de la orden. Con motivo del día de san Agustín, fray Luis pronuncia un sermón muy bien estudiado por Béhar (2011), donde "Agustín es el doctor por antonomasia y su doctrina ilumina la iglesia como el Sol alumbra al mundo, consistiendo entonces la verdadera sabiduría en un deseo de igualarlo" $(2011,45)$, de manera que el tópico del sabio que se identifica con el Sol adquiere un matiz doctrinal propio de la orden: " $\mathrm{El}$ ascenso hacia la luz divina es al mismo tiempo una conversión interior, en lo más íntimo del ser, donde se revela la luz" (2011, 51). Así, no es de extrañar que el propio fray Luis deje clara, en varios pasajes de De los nombres de Cristo, la relación entre este y el Sol. Por espigar, solo un par de ellos, en el nombre fesús escribe: "Que como sin la luz del sol no se ve, porque es fuente general de la luz, así sin la comunicación deste grande Jesús, deste que es salud general, ninguno tiene salud" (León 2008, 477). En el nombre "Esposo", leemos:

De manera que, como una nube en quien ha lanzado la fuerza de su claridad y de sus rayos el sol, llena de luz y, si aquesta palabra aquí se permite, en luz empapada, por dondequiera que se mire es un sol, así, ayuntando Cristo no solamente su virtud y su luz, sino su mismo cuerpo con los fieles y justos, y como mezclando en cierta manera su alma con la suya dellos, y con el cuerpo en la forma que he dicho, les brota Cristo, y les sale afuera por los ojos, y por la boca, y por los sentidos. $(2008,300)$

Incluso en un poema como "De la vida del cielo", Salstad ha propuesto que "it is possible to see an allusion in the last verse to Christ as the counterpart of the sun-god Apollo, a deity associated with music" (228).

De regreso ahora al poema, podemos advertir que la lógica neoplatónica con que anuda su inicio es absoluta y nada casual. Apolo despeja el camino al alma de la niña, en virtud de su papel, para la tradición neoplatónica, de responsable de llevar a cabo la unión del intelecto al alma en el descenso de esta hacia el cuerpo (Allen 166). Sin embargo, hay más, consecuencia de nuestra argumentación. Si fray Luis celebra el nacimiento de la hija de una ilustre familia, si doña Tomasina guarda en sí tanta luminosidad que irradia más luz que el propio Sol, su guía no podía ser otro que Apolo, divinidad solar por excelencia, benigna y dadora de vida, la que acaba de recibir la propia niña. Si doña Tomasina necesitaba en su nacimiento una mediación que acompañara su alma en su camino hacia el cuerpo, no hay otra mejor ni más segura para ella: Apolo, es decir, el Sol, es decir, el propio Cristo. 
La segunda cuestión de interés la ofrece la vertiente astrológica de la oda. Sería una temeraria inexactitud afirmar que fray Luis fuera un defensor de la astrología en el sentido más estricto adquirido por el término en el Renacimiento. Un acercamiento explícito a la magia natural o la defensa de los pronósticos astrológicos no hubieran sido las mejores ideas en alguien vigilado de cerca por la Inquisición. No quiere esto decir que la lírica del Renacimiento no prestara atención a una cierta veta astrológica. Si bien es cierto que no era demasiado militante, fray Luis no dejó de interesarse por una doctrina que el neoplatonismo renacentista incorpora más como catalizadora en la creación de formas de cultura que bajo el opaco ropaje del ocultismo y las doctrinas esotéricas (Garin 1981a, 85-116), siempre bajo el aserto según el cual Astra inclinant, sed non obligant. ${ }^{14}$

"Astronomía y astrología confundíanse en aquel tiempo, incluso en las mentes de los espíritus más clarividentes del renacimiento", apuntaba Macrì (348); y fray Luis será una de ellas. Ya en sus retratos, Pacheco afirmaba que fray Luis fue "gran astrólogo i judiciario, aunque lo usó con templança" (70). Tanto es así que, según explica Macrì, “en 1570 Fr. Luis fue adiestrado en la astrología judiciaria por un cierto Poza, licenciado en derecho canónico, uno de cuyos libros de fórmulas mágicas, que aquel le había consignado, quemó fray Luis, no antes de haber ensayado alguna" $(348),{ }^{15}$ en lo que se ha llegado a leer como un circunstancial extravío del agustino, fruto de su curiosidad científica (Bell 276). Más allá de anécdotas con más o menos tinte legendario, "la presencia de la astronomía en la obra poética de fray Luis no es un mero adorno, sino una preocupación y especialidad de fray Luis" (Flórez Miguel 361), muy en sintonía con las preocupaciones culturales de la época. Efectivamente, en buena parte de sus composiciones fray Luis no solo mirará al cielo estrellado en busca de aliento e inspiración poéticos, sino que tomará "imágenes y relaciones de la demonología pitagórico platónica y de la astrología del Renacimiento, atribuyéndoles significados cristianos" (Macrì 336).

14. Guy $(1989,48)$ verá una cierta inclinación de fray Luis hacia la cuestión astrológica en unos versos del poema “A Felipe Ruiz" (León 2006, 66-74): "Veré los movimientos celestiales, / ansí el arrebatado, / como los naturales; / las causas de los hados, las señales" (vv. 52-54). Ver también la dedicatoria a don Pedro Portocarrero: "Entre las ocupaciones de mis estudios, en mi mocedad, y casi en mi niñez, se me cayeron como de entre las manos estas obrecillas, a las cuales me apliqué más por inclinación de mi estrella, que por juicio o voluntad" $(2006,3)$.

15. Ver Bell $(277$, n. 15) y Vicente. 
Así las cosas, comienza el descenso del alma de doña Tomasina hasta su cuerpo, tutelada por Apolo. En dicho descenso, escribe fray Luis a la niña:

Diéronte bien sin cuento, con voluntad concorde y amorosa

quien rige el movimiento sexto, con la diosa, de la tercera rueda poderosa. (vv. 21-25)

El bien sin cuento que recibe el alma de doña Tomasina proviene de Júpiter y Venus (Macrì 316; Ramajo Caño 29, 545). El primero en su figura de rey y protector del cielo, fuente de armonía universal, desde la perspectiva de principal dios de los romanos, significativamente "Iupiter Lucentius (dios de la Luz)" (Sechi Mestica 149); la segunda en tanto que deidad dispensadora de belleza y amor a la niña. Todo ello, además, consiguiendo evitar la influencia de Saturno, "de tu belleza rara / el envidioso viejo mal pagado" (vv. 26-27), y del "fiero Marte airado [que] el camino dejó desocupado" (vv. 29-30).

Nos interesa señalar la naturaleza luminosa del "bien sin cuento" que Júpiter y Venus trasladan a la niña. No es algo exclusivo de esta composición. Lo encontramos en la Noche serena cuando, avanzada la oda, fray Luis enumera el orden de los planetas:

la luna cómo mueve

la plateada rueda, y va en pos della

la luz do el saber llueve,

y la graciosa estrella

de amor la sigue reluciente y bella;

y cómo otro camino

prosigue el sanguinoso Marte airado,

y el Júpiter benino,

de bienes mil cercado,

serena el cielo con su rayo amado;

rodéase en la cumbre

Saturno, padre de los siglos de oro;

tras él la muchedumbre

del reluciente coro

su luz va repartiendo y su tesoro. (vv. 46-60) 
El reluciente coro que reparte su luz, la misma que llueve de la plateada rueda de la Luna, Júpiter serenando el cielo con su rayo, todos ellos demuestran que la influencia de los planetas llega al alma en forma de luz. Y la imagen no es baladí ni casual, ni un mero símbolo fosilizado. Antes al contrario, supone una densa elaboración de la filosofía neoplatónica que conviene explicar para entender el significado último del poema de fray Luis a doña Tomasina.

En el tercer libro del De vita, Ficino se plantea la cuestión de los talismanes. Cuando habla de cómo crearlos, expone que "pueden así captarse en un receptáculo de esta guisa las influencias celestiales y las afines a ellas. Por citar un ejemplo, en el orden solar [se hallarían] entre los metales, el oro, entre las piedras el carbunclo o la pantaura" $(2006,124)$. Estas influencias se traducirían en ciertas consecuencias beneficiosas para el hombre:

Por lo mismo, cuando los astrólogos dicen que las luces, esto es, los colores, las figuras y los números, tienen grandísimo poder para predisponer nuestras sustancias materiales a las influencias celestes, no debes negar temerariamente, como ellos dicen, esta afirmación. (135)

Lo interesante, con todo, es que dichas influencias se transmiten a través de la luz que irradian los astros:

para poner ya fin a las divagaciones, concluyamos que si los rayos de las estrellas penetran inmediatamente toda la tierra, no es cosa fácil negar que penetran al instante un metal y una piedra cuando se esculpen en ellos imágenes, y que imprimen en ellos dotes admirables o al menos de cualquier género, dado que también en las profundidades de la tierra generan cosas preciosísimas. $\mathrm{Y}$, ¿quién podrá negar que los rayos penetran a través de todas estas cosas? (130)

Esta capacidad dinámica de la luz concuerda a la perfección con una de sus atribuciones más importantes para los filósofos neoplatónicos. En un pasaje memorable del De lumine, Marsilio Ficino explica que la luz es "vínculo del universo", ${ }^{16}$ nudo en el que todo se condensa, por el que todo circula, convirtiéndose así en "la chiave interpretativa della struttura reale del cosmo e illuminarne le più intime strutture, le connessioni e i rapporti che ne costituiscono la fondamentale bellezza e armonía" (Vasoli 1988, 64). Este carácter

16. "Lumen est vinculum universi" (1962, 981); "la lumière est le lien de l’Univers" (1981, 66). 
integrador de la luz le permite ser la instancia a través de la cual los astros proyecten al hombre su influencia.

Por eso, el tapiz luminoso del cielo fue una cuestión que preocupó a Marsilio Ficino. En otro pasaje del De lumine habla, para describir el firmamento, de una risa del cielo que enviara sus efectos hacia toda la creación. Merece la pena consignar entero el octavo epígrafe del tratado, de significativo título:

"La risa del cielo enviada por el gozo de las divinidades, esto es, la luz, calienta y deleita todas las cosas"

Que la luz es la risa del cielo, enviada por el gozo de los espíritus celestes se demuestra porque, cada vez que los hombres se ríen y alegran su espíritu, resplandecen interiormente, su espíritu se dilata, su rostro parece asimismo resplandecer, sobre todo los ojos -extremadamente celestes-, que con la risa ejecutan un movimiento circular, a semejanza del cielo. Con las lágrimas, por el contrario, todo se oscurece, se estrecha, se entumece. En verdad, los rayos procedentes de los astros que sonríen, igual que ojos de las inteligencias divinas, calientan y engendran todas las cosas, dirigidos con alegría y bondad a las semillas, del mismo modo que la mirada del avestruz sobre su huevo. Su virtud infunde un calor natural en todos los seres, haciendo nacer la vida, fortaleciéndola y aumentándola. De ahí que todas las cosas busquen el placer, pues son engendradas no solo por la voluptuosidad terrena, sino también por el gozo celeste. Y es que, ¿quién negaría que las potencias divinas todo lo mueven y engendran gracias a una alegre disposición, si advertimos tanto en la naturaleza como en el arte todas las cosas son engendradas y perfeccionadas con placer? ${ }^{17}$

17. “«Risus coeli ex numinum gaudio proficiscens, id est, lumen omnia fovet atque delectat» Quod lumen sit risus coeli ex spirituum coelestium gaudio proficiscens, indicant homines, qui quotiens laetantur spiritu, ridentque vultu, splendent certe intus, dilatanturque spiritu, vultu quoque splendere videntur, oculis maxime, qui ma xime sunt coelestes, quique in risu motum coeli instar efficiunt circularem. In lugentibus autem contra obtenebrantur, restringuntur, torpent omnia. Radii vere ex stellis ridentibus tanquam divinarum mentium oculis, benignissime laetissimeque directi in semina rerum, non aliter omnia fovent generantque, quam strutii aspectus in ovum. Illorum enim virtute calor naturalis cunctis inferitur, unde vita oritur, alitur, augetur. Hinc sic ut omnia voluptatem appetant, quia non modo voluptate terrena, sed etiam coelesti laetitia generantur. Quis autem neget numina laeto quodam affectu omnia movere atque generare? Cum et ab animalium natura et ab arte omnia voluptate procreari atque perfici videamus" (1962, 978-79); “«Le rire du ciel provoqué par la joie des puissances divines, c'est-à-dire la lumière, réchauffe et réjouit tout» On se persuadera que la lumière est le rire du ciel provoqué par la joie des esprtis célestes, en observant que, chaque fois que les hommes se réjouissent en esprit et que leur visage rit, ils resplendissent intéreurment et leur esprit 
Reynaud (197-200) ha llamado la atención sobre el papel que tiene la risa en la obra de Ficino, con especial protagonismo en el De lumine y el De raptu Pauli. Para el filósofo florentino, en ella se encontraría "l'expression la plus fidele de la bonté de l'âme" (198). ${ }^{18}$ Efectivamente, por tratarse de uno de los puntos del cuerpo donde se entrelazan lo corporal y lo espiritual (Deramaix 193) ${ }_{19}^{19}$ la personificación de la imagen, según la construcción del cielo como un "«makrantropos» [que] semeja a un hombre" (Soria Olmedo 107), adquiere pleno vigor platónico. Al ser la sonrisa expresión del alma -y esta, como veremos en el siguiente epígrafe, no es sino luminosa-, la analogía se anuda más si cabe para la filosofía neoplatónica: la risa es expresión luminosa del alma, la risa del cielo es expresión luminosa de los “espíritus celestes". Luminosos ambos, como luminosa es la articulación de Ficino de la generación y perfección del mundo, a partir del concepto del placer, del gozo de la mens: "Recréate solamente en aquella luz, sin la cual no puedes gozar ni de ti, ni de cualquier otra cosa". ${ }^{20}$ La risa del cielo es fecundidad, placer y poder vivificador. Es un gozo del hombre y del mundo, correspondiéndose uno al otro, con la luz como puente entre ambos niveles. Desde esa perspectiva podemos entender que, para el poeta o el filósofo del Renacimiento, las almas de los hombres y las almas de los cuerpos celestes entren en contacto gracias a los rayos que parten de las "innumerables luces", transmitiendo consigo el poder benéfico de su "virtud", su "calor natural", "el cual hace nacer la vida, la fortalece y la aumenta".

Fray Luis aborda este cruce de imágenes, al hablar del hombre "como un medio entre lo espiritual y lo corporal", "como dijeron antiguamente, un me-

se dilate, et leur visage paraît lui aussi resplendir, en particulier leurs yeux, qui sont extrêmement célestes et qui, lors du rire, exécutent, à l'instanr du ciel, des mouvements circulaires. Dans les larmes, au contrarire, tout s'obscurit, se resserre, s'engorduit. En vérité, les rayons provenant des astres qui rient comme les yeux des intelligences divines réchauffent et engendrent toutes choses en étant dirigés avec liesse et bienveillance sur les semences, exactement comme le regard de l'autruche sur son aeuf. En effet, leur vertu infuse une chaleur naturelle dans tous les êtres, laquelle fait naître la vie, la fortifie et l'augmente. De là vient que tous recherchent le plaisir, puisqu'ils sont engendrés non seluement par la volupté terrestre, mais encore par la joie céleste. Mais qui niera que les puissances divines meuvent et engendrent tout grâce à une joyeuse disposition, puisque tant la nature des êtres vivants que l'art nous montrent que tout s'engendre et se perfectionne dans le plaisir?” $(1981,62)$.

18. Ver Curtius (598-601) para un repaso a la imagen en la tradición lírica occidental.

19. "Símbolo de la realidad psíquica, y la manifestación de una sensibilidad atenta a sí misma [...] a la vez un accidente del organismo y un dato simbólico", dirá Chastel (426).

20. "Gaude dumtaxat lumine, sine quo neque aliis potes unquam, neque teipsa gaudere" (1962, 966); "Dilectati [mens] solamente di quel lume, sanza el quale non puoi o d'altre cose mai o vero di te medesima godere" (1952a, 967). 
nor mundo o un mundo abreviado" $(2008,44)$. En el segundo de los textos introductorios de De los nombres de Cristo, leemos que:

Consiste, pues, la perfección de las cosas en que cada uno de nosotros sea un mundo perfecto, para que por esta manera, estando todos en mí y yo en todos los otros, y teniendo yo su ser de todos ellos, y todos y cada uno de ellos teniendo el ser mío, se abrace y eslabone toda aquesta máquina del universo, y se reduzga a unidad la muchedumbre de sus diferencias. $(2008,21)$

Como explica Francisco Rico, esta noción del hombre como microcosmos es fruto de la armónica "unidad cósmica", de modo que la contemplación del firmamento no debe entenderse como "una mera afinidad intelectual; o, si lo es, se apoya en un fundamento físico innegable, en un sistema de la Naturaleza que es al tiempo sistema de la vida religiosa y moral, de la política, de la justicia" (2005, 143). En esta misma línea, y acercándose más a nuestro interés luminoso, Macrì escribe que la contemplación del firmamento supone para fray Luis

hermandad, concordia, mutua moderación de rayos y virtudes de las estrellas, mensajeros entusiastas, quienes con voz y sin ruido acometen a nuestras almas y les aconsejan alcanzar su paz en sí mismas, de manera que nuestro interior mundo corresponde a su orden y concierto, y dentro de nosotros se difunde serenidad. (95)

El hermoso arranque del nombre "Príncipe de paz" en De los nombres de Cristo da muestra del papel de la luz en la consecución de esta armonía: "Cuando la razón no lo demostrara, ni por otro camino se pudiera entender cuán amable cosa sea la paz, esta vista hermosa del cielo que se nos descubre agora, y el concierto que tienen entre sí que luzen en él, nos dan dello suficiente testimonio" (León 2008, 245). Es posible una conexión real y efectiva con el firmamento, es decir, con el universo, con el anima mundi, efectiva y en absoluto figurada, a través de los rayos de luz que mandan las estrellas. Lo comprobamos en la manera en que fray Luis continúa su argumentación:

El ejército de las estrellas, puesto como en ordenanza y concertado por sus hileras, luce hermosísimo, y adonde [...] como hermanadas todas, y como minores, se hacen muestra de amor y, como en cierta manera, se reverencian unas a otras, $y$ todas juntas templan a veces sus rayos y sus virtudes, reduciéndolas a una pacífica unidad de virtud, de partes y aspectos diferentes, compuesta, universal y poderosa sobre toda manera 
[...] Porque, si estamos atentos a lo secreto que en nosotros pasa, veremos que este concierto y orden de las estrellas, mirándolo, pone en nuestras almas sosiego, y veremos que con solo tener los ojos enclavados en él con atención, sin sentir en qué manera, los desseos nuestros y las afectiones turbadas, que confusamente movían ruido en nuestros pechos de día, se van quietando poco a poco y, como adormeciéndose, se reposan tomando cada una su asiento y, reduciéndose a su lugar proprio, se ponen sin sentir en sujetión y concierto. (2008, 244-45)

La luz es así herramienta nodal para la visión del firmamento neoplatónico y luisiano, pues su naturaleza a la vez física y espiritual explica y justifica, incluso teológicamente, su poder sobre el alma del que la contempla y la recibe: "Solo la luz tiene, a sus ojos, el don de elevarnos y transportarnos de alegría, pero se trata en el fondo de luz espiritual, de esa «luz» tan amada que nos dispensa Cristo" (Guy 1960, 252).

Nuestro poema adquiere desde esta óptica una interesante dimensión. Fray Luis expresa sus deseos de que el alma de doña Tomasina entre en comunión, desde el momento mismo de su nacimiento, con todo el universo, en virtud de una armonía que viene regulada y transmitida en forma de luz. No de otro modo que el luminoso puede entenderse el "bien sin cuento" que sobre el alma de la niña llueve en su descenso. Más aún, esa intención de fray Luis se confirma si atendemos al certero apunte de Asensio (100), cuando escribe que los tres planetas que influyen en doña Tomasina -el Sol, en tanto que Apolo, Venus y Júpiter- vendrían a formar lo que Ficino llamaba "las tres Gracias del cielo y de las estrellas". Conocidísima en la iconología artística renacentistas -desde La primavera de Botticelli hasta Rubens-, la concordia que las tres Gracias transmiten al formar un círculo con sus manos entrelazadas está estrechamente relacionada con la estructura armónica del universo (Wind 39$62 ; 115-27) .{ }^{21} \mathrm{Y}$ en ese marco de armonía encuadra fray Luis a la hija del marqués de Alcañices, trascendiendo, creemos, la "faceta jovial y juguetona, presente en el poema de fray Luis", que detecta Asensio (101).

Doña Tomasina recibe un privilegiado baño de luz astral, sumergiéndose en la más plena armonía con la creación. Los versos que fray Luis le dedica no hacen entonces sino cristalizar un modo de conocimiento, una manera de comprender el universo que no se aleja demasiado de los planteamientos de

21. Ver también Chastel (269-71) y Gombrich (55-62). 
sus poemas mayores. No solo celebra su nacimiento, sino que busca propiciarle la mayor felicidad, el mayor gozo, en forma de una luz que indica pura concordia con el cosmos. En su raíz, la oda a Tomasina de Borja tiene un funcionamiento, una lógica, análogos, por ejemplo, a los de la "Noche serena". En ambos el uso de la luz de los planetas pone en juego "algo más que meras metáforas. Es el universo tal y como lo entienden los cristianos neoplatónicos" (Vicente 317).

IV

El descenso del alma de doña Tomasina finaliza y, con él, el meandro astrológico del poema. No se agota ahí, sin embargo, su sustrato neoplatónico. Merece la pena prestar atención al momento en que el alma de la hija de Alcañices llega a su cuerpo y a cómo fray Luis, en boca de Apolo, describe la relación entre ambos:

Deciende en punto bueno, espíritu real, al cuerpo hermoso, que en el ilustre seno te espera, deseoso por dar a tu valor digno reposo. (vv. 36-40)

La armonía, una de las categorías centrales en el análisis del poema, reina entre el alma de la niña y el cuerpo que la albergará. Este no supone ninguna mancha, ningún tipo de degradación para el alma. Al contrario, es "digno reposo" para el "valor" de doña Tomasina, del mismo modo, por cierto, que en el poema que fray Luis dedica a la Virgen, esta era "digno reposo" para "la Deïdad".

La relación se manifiesta de manera ejemplar en la duodécima lira del poema:

El cuerpo delicado,

como cristal lucido y transparente,

tu gracia y bien sagrado,

tu luz, tu continente,

a sus dichosos siglos represente. (vv. 56-60)

El cuerpo es entendido así como "continente" del alma, algo que la recubre, y la guarda en su interior. Con todo, lo que nos interesa es la claridad y sencillez con que, desde el punto de vista del neoplatonismo, se define esta lógica de la relación entre cuerpo y alma a partir del ámbito de la "luz". Para el neo- 
platonismo renacentista el alma no es otra cosa que pura luz, merced a una interesante secuencia de pasos metafísicos. En el tercer libro de la Theologia platonica, Ficino (2001, I, 212-47) escribe que el alma es "verdadera conexión del universo [...], centro de la naturaleza, punto medio del universo, rostro de todas las cosas, cadena, nudo y vínculo del mundo", ${ }^{22}$ en virtud del lugar privilegiado que ocupa en su sistema ontológico, en tanto que cruce de las diversas instancias que lo componen: "Dios, la mente, el alma, la naturaleza y la materia" (Ficino 1986, 27). ${ }^{23}$ Será en el octavo libro donde Ficino, con un hermoso juego de palabras, apriete dicho nudo. Allí escribe que "la luz no es otra cosa que un alma visible - de ahí que todas las cosas nazcan a la vida gracias a ella-, el alma es luz invisible". ${ }^{24}$ Una luz que, según explica el mismo Ficino, y esto será clave para entender el mecanismo neoplatónico del poema, conoce diversas gradaciones desde su primera emanación espiritual desde la divinidad hasta el propio color que advertimos en los objetos:

La luz es una emanación en cierto modo espiritual, tan repentina como extendida por los cuerpos -sin alterarlos en su naturaleza-, emanación de un cierto brillo en los cuerpos diáfanos -es decir, transparentes-, emanación de color en los que la obstaculizan, emanación, en todos los cuerpos, de la cantidad, figura y movimiento. Prueba a fundir en uno solo todos los géneros de color, ¿qué será este todo, sino una luz omnicolor, o una luz hecha ya opaca, en la materia de la tierra más sólida y oscura? Quítale la tierra que tiene mezclada, ¿qué quedará a no ser una cualidad, es decir, claridad y acto de transparencia, como el color es acto de lo opaco? Pues el color es luz opaca y la luz color claro, es decir, una cierta floración y pujanza del cuerpo transparente y de los colores, que es monocolor en acto y en potencia omnicolor. (2004, 337-39)

22. "Et quia ipsa vera est universorum connexio [...] centrum naturae, universorum medium, mundi series, vultus omnium nodusque et copula mundi" $(1962,108)$; "true bond of everything in the universe [...] nature's center, the mean of everything in the universo, the sucession or chain of the world, the countenance of all things, and the knot and bond of the world" (2001, I, 243).

23. Ver, por supuesto, al Pico della Mirandola que habla de "vínculo unificador, o mejor dicho, himno nupcial del mundo" (99). Ficino retoca ligeramente la cadena del ser plotiniana basada en sus diferentes hipóstasis: Uno, Inteligencia, Alma, Materia (Plotino 17-48), "en parte para hacerlo más simétrico y en parte para asignar al alma humana el lugar privilegiado en su centro, dando así una especie de engaste y sanción metafísicos a la doctrina de la dignidad del hombre, que heredó de sus predecesores humanistas" (Kristeller 1970, 63).

24. "Lumen nihil aliud est nisi visibilis anima, unde per hoc omnia reviviscunt; anima vero lux invisibilis" (1962, 288); "Light is nothing other than visible soul (whence all things come to life again because of it) and soul is invisible light" (2001, II, 347). 
A la luz de estos testimonios ficinianos, se comprende que no haya mera retórica en el hecho de que el cuerpo de la niña, por ser tan "delicado", se conciba "como cristal lucido y transparente", sino profundo conocimiento de la filosofía neoplatónica. A pesar de que, por ejemplo, Hildner haya mostrado ciertas dudas ante el hecho de hacer casi igual de transparentes cuerpo y alma, ${ }^{25}$ a poco que analicemos el poema desde la órbita del neoplatonismo luminoso ficiniano, estas dudas se disipan, no tienen "nada de particular" (Ramajo Caño 546). Lo vio bien Macrì, para quien "el afinamiento estilístico de fray Luis reside completamente en el acorde entre el «espíritu real» y el «cuerpo hermoso», la alteza de la honestidad y la lúcida transparencia del cristal femenino" (51).

No hay en el poema tanto un "intercambio" (Pérez-Abadín 494) entre el cuerpo y el alma de la niña como la incorporación de esta "a un cuerpo perfectamente espiritualizado" (Rodríguez 250). León Hebreo, en el primero de sus Diálogos, escribe sobre esta capacidad del alma para, merced a sus virtudes y excelencia, purificar luminosamente el cuerpo: " $\mathrm{El}$ amor ardiente e insaciable hacia la sabiduría y la virtud de las cosas honestas hacen divino nuestro entendimiento humano y convierten nuestro frágil cuerpo, vaso de corrupción, en instrumento de espiritualidad angélica" (57). Fray Luis lleva al extremo esta capacidad espiritualizadora del alma, que se consuma en la descripción del cuerpo de la niña como un brillo definitivo, establecida en la transparencia del cristal más puro. Deja muy claro el funcionamiento de esta lógica luminosa en dos pasajes de su obra en prosa. El primero pertenece a De los nombres de Cristo. En él habla en los siguientes términos del nacimiento de Cristo: "Porque el resplandor infinito de Dios reverberaba su hermosura en el alma, y el alma, con este resplandor, hecha una luz, resplandecía en el cuerpo, que, vestido de lumbre, era como una imagen resplandeciente de los resplandores divinos" (2008, 373). El segundo lo encontramos en La perfecta casada:

Porque así como la luz encerrada en lanterna la esclarece y traspasa, y se descubre por ella, así el alma clara y con virtud resplandeciente por razón de la mucha hermandad que tiene con su cuerpo, y por estar íntimamente unida con él, le esclarece a él, y le figura y compone tanto cuanto es posible de su misma composición y figura. $(1987,168)$

25. "In the Doña Tomasina poem, Fray Luis breaks his normal pattern and gives us a luminous soul in a equally luminous and transparent body" (151). No llega, además, a entender que la niña pueda hacer sombra al Sol (153). 
Los dos pasajes, en particular este último, son fundamentales porque explican buena parte de la fenomenología neoplatónica luminosa del cuerpo. Son perfectos ejemplos de que se trata de un "cuerpo expresivo [...] espiritualizado en tanto que expresión transparente del alma interior" (Rodríguez 93). La relación entre cuerpo y alma se establece a partir de esta noción de expresión, muy extendida por todo el Renacimiento, ${ }^{26}$ que encontrará perfecto instrumento de formulación en el símbolo luminoso. En un pasaje decisivo y transparente en cuanto a lo que venimos comentando explica Ficino que "la luz [es] una verdad que se despliega al exterior" (2004, 341).

No otra cosa es lo que sucede en la lira que venimos comentando del poema a doña Tomasina de Borja. Decir que su cuerpo es como cristal, concederle el don de la transparencia será, siguiendo la lógica lumínica de Marsilio Ficino, dotar a la niña del tipo de cuerpo que menos se verá lastrado por lo grávido y terrestre de la materia, que más y mejor permitirá pasar la luz. Los brazos, el torso, el rostro de la niña son puro cristal porque a través de ellos la luz de su alma no encuentra apenas impedimento a la hora de encontrar el aposento en el cuerpo después del descenso y, a la vez, de expresarse hacia el exterior. La espiritualización del cuerpo de la hija de Alcañices deriva en un poder tal de expresión luminosa del alma a través de aquel, que casi vence la resistencia de la materia, lo que de opaca pudiera tener. Tan alta es su luz. Tomasina se convierte en una forma humana del paradigma renacentista del diamante como piedra preciosa por excelencia, asociado, frente a la gema medieval y su luz divina encapsulada, "a la incorruptibilidad, a la dureza, al brillo, a la transparencia, al sol” (Gambin 285). La hija del marqués de Alcañices tiene el cuerpo de cristal porque, siguiendo el paralelo de la luz del alma con la luz física y fundiéndolas lo más posible en un solo término, se po-

26. Ver el estudio de Panofsky (2008, 209-17) sobre la dialéctica neoplatónica del desnudo. Aunque su análisis tiene lugar desde una perspectiva iconológica, sus conclusiones no pueden ser más reveladoras. Explica el sabio alemán que en el Renacimiento se produce un cambio en las representaciones de la desnudez, desde el "carácter estrictamente eclesiástico" del pensamiento medieval, hacia el "plano secular" quattrocentista (215). Con todo, lo más interesante es el trasfondo que sostiene este cambio iconológico. Para Panofsky "la desnudez como tal, especialmente cuando se la compara con su contraria, llegó a ser entendida como un símbolo de la verdad en un sentido filosófico general [...] y con la aparición del movimiento neoplatónico llegó a significar lo ideal e inteligible por oposición a lo físico y sensible, la esencia simple y «verdadera» por oposición a sus «imágenes» varias y cambiantes" (216-17). Ver también Rodríguez (153): "La verdad ha de ser desnuda, [...] hay que quitarle toda su materia superflua para que aparezca resplandeciente en sí misma, para que se revele a los ojos humanos en toda su pureza estricta". 
dría explicar, con León Hebreo (310), que "la belleza de la luz del sol se refleja con mayor perfección en los cuerpos delgados y transparentes que en los opacos".

Es cierto que la pura luminosidad del cuerpo de la niña se puede integrar "en la mentalidad petrarquista de elevación y dignificación de lo corporal" (Ramajo Caño 546). Coincidiendo con Ramajo en dicha dignificación, en la que la luz desempeñaría un papel principal, que fray Luis trate así el cuerpo de la niña tiene menos que ver, en el caso concreto de este poema, con lo corporal que con la edad de doña Tomasina. Fray Luis encuentra en la niña la oportunidad de escribir sobre el cuerpo que más cerca se encontrará de la pureza, del "cantar sabroso no aprendido" de las aves que representaban la naturaleza verdadera. El cuerpo recién nacido de la niña, apenas estrenado por el alma, no ha sido aún tocado por lo mundano y permite al alma resplandecer a su través con la inusitada fuerza que nos sorprende al leer el poema. Solo ahí, por situarse más cerca del mundo de "la verdad" platónica e ideal que de "lo fingido" terrenal (v. 70), fray Luis admitirá que un cuerpo pueda espiritualizarse y acercarse a la luminosidad del alma. La conjunción de un alma que ha recibido el influjo benéfico y luminoso de las Tres Gracias, de una dinastía de la que es "ilustre y tierna planta" y del cuerpo puro de la recién nacida permite que fray Luis no tenga ningún reparo en utilizar la imaginería petrarquista a la que aludía Ramajo. La luz atraviesa con tanta fuerza el cuerpo de la niña, que hace pedir a fray Luis que "los dos tus ojos sean / dos luces inmortales, / que guíen al sumo bien a los mortales" (vv. 53-55). No se trata tanto, como pretende Macrì, de que esas dos luces sean "lo que vulgarmente llamamos las luces del alma" (318), sino de que, como afirma Alarcos Llorach, "la inmortalidad de la luz de los ojos se postula como consecuencia de la futura animación del cuerpo, como muestra de las «vivas señales» de la beldad del alma reflejada en el rostro" (144). Es la luz del alma la que se expresa, la que traspasa, iluminándola, la pupila física, en la descripción que de doña Tomasina se hace en el poema.

Por eso mismo, no existe el peligro de que el amor terreno acabe contaminando la pureza de ese cuerpo:

¡Ay tristes!, ¡ay dichosos

los ojos que te vieren!; huyan luego,

si fueren poderosos,

antes que prenda el fuego,

contra quien no valdrá ni oro ni ruego. (vv. 71-75) 
$\mathrm{Ni}$ el oro de los negocios temporales ni el ruego de los amores terrenales ${ }^{27}$ podrán, pasado el tiempo, con la pureza de un alma que traspasa e impregna de luz el cuerpo de la niña, purificándolo más si cabe, ya que "the virtue of the soul that is descending to earth is so great that the author believes its incorruptibility to be assured" (Hildner 150-51).

Con toda la purificación y vitrificación del cuerpo, no debemos olvidar algo que en el neoplatonismo se constituye como axioma desde el primer momento y que tal vez motivó la lógica extrañeza de Hildner ante tanta luz corporal: el alma siempre estará jerárquicamente por encima del cuerpo. Fray Luis lo deja muy claro cuando escribe:

Alma divina, en velo

de femeniles miembros encerrada, cuando veniste al suelo, robaste de pasada

la celestial riquísima morada. (vv. 16-20)

En esta lira, que aparece antes de la descripción del cuerpo de doña Tomasina, y de que su alma emprenda el descenso hacia la tierra, fray Luis deja claras dos cosas. En primer lugar, que el alma de la niña procede de la más alta de las esferas, del Paraíso, "la celestial riquísima morada", libre por eso de la mancha material (Ramajo 545) y plena de luz. En segundo lugar, aparece una noción que marca la supremacía del alma sobre el cuerpo, y que hará fortuna a lo largo de la lírica renacentista, no solo española, sino europea. Hablamos de la noción del velo que constituyen los "femeniles miembros" de la niña. Incluso en un poema que dignifica tanto al cuerpo como este, fray Luis no puede dejar de apuntar que el alma de Doña Tomasina está "encerrada", constreñida después de su paso por los espacios abiertos de los astros. Si el alma es luz, y la verdadera luz, según explicaba Ficino se obtenía por un proceso como de destilación, en el que se iba separando de la tierra, de las impurezas grávidas que la ataban al mundo sensible, por muy digno y cristalino que sea un cuerpo, no dejará de ser una envoltura que impida la libre radiación de su luz, su ascenso hacia el firmamento, su patria originaria. No dejará de ser un velo. Eso sí, uno de los más puros y hermosos de la historia de nuestra lírica.

27. Ver la segunda de las odas "A Felipe Ruiz" (2006, 79-85): "Quien de dos claros ojos / y de un cabello de oro se enamora, / compra con mil enojos / una menguada hora, / un gozo breve que sin fin se llora" (vv. 16-20). 


\section{OBRAS CITADAS}

Agustín de Hipona. "Del Génesis a la letra". Obras de San Agustín. Vol. 15. Ed. Balbino Martín. Madrid: Biblioteca de Autores Cristianos, 1957. 4631031.

Alarcos Llorach, Emilio. El fruto cierto: estudios sobre las odas de fray Luis de León. Madrid: Cátedra, 1996.

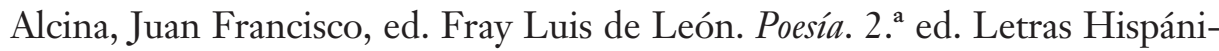
cas 184. Madrid: Cátedra, 1987.

Allen, Michael J. B. "Life as a Dead Platonist". Marsilio Ficino: His Theology, His Philosophy, His Legacy. Eds. Michael J. B. Allen y Valery Rees. Boston: Brill, 2002. 159-78.

Asensio, Eugenio. De Fray Luis de León a Quevedo y otros estudios sobre retórica, poética y humanismo. Salamanca: Universidad de Salamanca, 2005.

Auerbach, Eric. Mimesis: la representación de la realidad en la literatura occidental. Trads. I. Villanueva y E. Ímaz. México: Fondo de Cultura Económica, 1950.

Béhar, Roland. "Lecturas y traducciones de Ficino en Castilla bajo Isabel la Católica". Estudios sobre la Edad media, el Renacimiento y la temprana modernidad. Eds. Francisco Bautista y Jimena Gamba. San Millán de la Cogolla: Instituto Biblioteca Hispánica del CiLengua/Sociedad de Estudios Medievales y Renacentistas/Seminario de Estudios Medievales y Renacentistas, 2010. 467-76.

Béhar, Roland. "Fray Luis de León y San Agustín: la Oratio in Laudem Divi Augustini". Criticón 111-112 (2011): 43-71.

Bell, Aubrey. Luis de León: un estudio del Renacimiento español. Barcelona: Araluce, 1927.

Bruno, Giordano. La cena de las cenizas. Ed. y trad. Miguel Ángel Granada. Madrid: Editora Nacional, 1984.

Chastel, André. Arte y bumanismo en Florencia en tiempos de Lorenzo el Magnífico. Trads. Luis López Jiménez y Luis Eduardo López Esteve. Madrid: Cátedra, 1982.

Copérnico, Nicolás. Sobre las revoluciones (de los orbes celestes). Ed. y trad. Carlos Mínguez Pérez. Clásicos del pensamiento 34. Madrid: Tecnos, 2001.

Cuevas, Cristóbal, ed. Fray Luis de León. Poesías completas. Nueva biblioteca de erudición y crítica 14. Madrid: Castalia, 2000.

Curtius, Erns Robert. Literatura y Edad Media latina. Trads. Antonio Alatorre y Margit Frenk Alatorre. México D. F.: Fondo de Cultura Económica, 1989. 
Deramaix, Marc. "Vident lumen oculi: Physique et métaphysique de la lumière et de la visión dans trois traités de Marsile Ficin”. Etudes sur la vision dans l'Antiquité classique. Ed. Laurence Villard. Rouen: Universités de Rouen et du Havre, 2005. 175-98.

Elia, Paola y María Jesús Mancho, eds. San Juan de la Cruz. Cántico espiritual y poesía completa. Biblioteca clásica de la Real Academia Española 44. Barcelona: Crítica, 2002.

Fernández Leborans, M. ${ }^{a}$ Jesús. "La noche en fray Luis de León: de la denotación al símbolo". Probemio 4 (1973): 37-74.

Fernández Leborans, M. Jesús. Campo semántico y connotación. Madrid: Cupsa, 1977. Fernández Leborans, M. J Jesús. Luz y oscuridad en la mística española. Madrid: Cupsa, 1978.

Ficino, Marsilio. "De raptu Pauli". Ed. Eugenio Garin. Prosatori latini del Quattrocento. Milano: Ricciardi, 1952a. 931-69.

Ficino, Marsilio. "De Sole”. Ed. Eugenio Garin. Prosatori latini del Quattrocento. Milano: Ricciardi, 1952b. 969-1009.

Ficino, Marsilio. Opera (Ripr. Fasc. dell'edizione di Basilea, 1576). Torino: Bottega d'Erasmo, 1962.

Ficino, Marsilio. "De lumine". Ed. Sylvain Matton. VV.AA. Lumiere et cosmos: courants occultes de la philosophie de la Nature. Paris: Albin Michel, 1981. 55-75.

Ficino, Marsilio. De amore: comentario a "El Banquete" de Platón. Ed. Rocío de la Villa Ardura. Madrid: Tecnos, 1986.

Ficino, Marsilio. De vita. Eds. y trads. Albano Biondi y Giuliano Pisani. Pordenone: Biblioteca dell'immagine, 1991.

Ficino, Marsilio. Platonic Theology. Eds. Michael J. B. Allen y James Hankins. 6 vols. Cambridge, MA: Harvard uP, 2001.

Ficino, Marsilio. "Quid sit lumen”. Trad. Pedro Jiménez Manzorro. Juan B. Díaz Urmeneta. La tercera dimensión del espejo: ensayo sobre la mirada renacentista. Sevilla: Universidad de Sevilla, 2004. 335-50.

Ficino, Marsilio. Tres libros sobre la vida. Ed. Mauricio Jalón. Trad. Marciano Villanueva Salas. Madrid: Asociación Española de Neuropsiquiatría, 2006.

Flórez Miguel, Cirilo. "El Sueño de Escipión y la astronomía en la obra y la poesía de fray Luis de León". La Ciudad de Dios 214 (2001): 347-69.

Gambin, Felice. "De una extraña melancolía: beber y tomar oro en La Dorotea de Lope de Vega". Literatura, sociedad y política en el Siglo de Oro (Barcelona/Gerona 21-24 de octubre de 2009). Eds. Eugenia Fosalba y Carlos Vaíllo. Barcelona: Universidad Autónoma de Barcelona, 2010. 269-95. 
García, Miguel Ángel. "Sin que la muerte al ojo estorbo sea": nueva lectura crítica de Francisco de Aldana. Mérida: Editora regional de Extremadura, 2010.

García Palacios, Joaquín. "Léxico de «luz» y «calor» en la Llama de amor viva". Ed. Otger Steggink. San fuan de la Cruz, espiritu de llama. Roma: Institutum Carmelitanum, 1991. 382-411.

García Palacios, Joaquín. Los procedimientos de conocimiento en San Fuan de la Cruz. Salamanca: Universidad de Salamanca, 1992.

Garcilaso de la Vega. Obra poética y textos en prosa. Ed. Bienvenido Morros. Barcelona: Crítica, 2007.

Garin, Eugenio. "Copernico e il pensiero del Rinascimento italiano". VV.AA. Copernico e la cosmologia Moderna (Convegno internazionale: Roma 3-5 maggio 1973). Roma: Accademia Nazionale dei Lincei, 1975. 13-26.

Garin, Eugenio. El zodiaco de la vida: la polémica astrológica del Trescientos al Quinientos. Trad. Antonio Prometeo Moya. Barcelona: Península, 1981a.

Garin, Eugenio. La Revolución Cultural del Renacimiento. Ed. Miguel Ángel Granada. Trad. Domènec Bergadà. Barcelona: Crítica, 1981b.

Gombrich, Ernst H. Imágenes simbólicas: estudios sobre el arte del Renacimiento, 2. Trad. Remigio Gómez Díaz. Madrid: Debate, 2001.

Guy, Alain. El pensamiento filosófico de Fray Luis de León. Trad. Ricardo Marín Ibáñez. Madrid: Rialp, 1960.

Guy, Alain. Fray Luis de León, 1527-1591. París: José Cortí, 1989.

Hildner, David J. Poetry and Truth in the Spanish Works of Fray Luis de León. London: Tamesis Books, 1992.

Kepler, Johanes. Conversación con el mensajero sideral. Ed. y trad. Carlos Solís. Madrid: Alianza Editorial, 2007.

Kristeller, Paul Oskar. Ocho filósofos del Renacimiento italiano. Trad. María Martínez Peñaloza. México D.F.: Fondo de Cultura Económica, 1970.

Kristeller, Paul Oskar. Il pensiero filosófico di Marsilio Ficino. Firenze: Le Lettere, 1988.

Lara Garrido, José, ed. Francisco de Aldana. Poesías castellanas completas. 2. a ed. Letras Hispánicas 223. Madrid: Cátedra, 1997.

Lauster, Jörg. "Marsilio Ficino as a Christian Thinker: Theological Aspects of his Platonism". Marsilio Ficino: His Theology, his Philosophy, his Legacy. Eds. Michael J. B. Allen y Valery Rees. Boston: Brill, 2002. 45-69.

León Hebreo. Diálogos de amor. Ed. Andrés Soria Olmedo. Trad. David Romano. Madrid: Tecnos, 2002. 
León, Luis de. La perfecta casada. Ed. Mercedes Etreros. Temas de España 177. Barcelona: Taurus, 1987.

León, Luis de. Poesía. Ed. Antonio Ramajo Caño. Biblioteca clásica de la Real Academia Española 38. Madrid: Galaxia Gutenberg, 2006.

León, Luis de. De los nombres de Cristo. Ed. Javier San José Lera. Biblioteca clásica de la Real Academia Española 39. Madrid: Galaxia Gutenberg, 2008. Macrì, Oreste. La poesía de Fray Luis de León. Salamanca: Anaya, 1970.

Mancho Duque, María Jesús. El símbolo de la noche en San fuan de la Cruz: estudio léxico-semántico. Salamanca: Universidad de Salamanca, 1982.

Maristany del Rayo, Joaquín. "Reportatum de Angelis: alcance, noticia y paralelismo con el corpus luisiano (Salamanca, curso 1570-1571)". Fray Luis de León: historia, humanismo y letras. Eds. Víctor García de la Concha y Javier San José Lera. Salamanca: Universidad de Salamanca, 1996. 341-55.

Pacheco, Francisco. Libro de descripción de verdaderos retratos de ilustres y verdaderos varones. Eds. Pedro Piñero y Rogelio Reyes. Sevilla: Diputación Provincial, 1985.

Panofsky, Erwin. Renacimiento y renacimientos en el arte occidental. Trad. M. ${ }^{a}$ Luisa Balseiro. Madrid: Alianza Editorial, 1975.

Panofsky, Erwin. Estudios sobre iconología. Madrid: Alianza Editorial, 2008.

Pérez-Abadín, Soledad. "El Genius Natalis en la oda IV de fray Luis de León". Bulletin Hispanique 97 (1995): 493-502.

Pico della Mirandola. "Discurso de la dignidad del hombre". Manifiestos del bumanismo: Petrarca, Bruni, Pico della Mirandola, Alberti. Ed. y trad. María Torrás. Barcelona: Península, 2000. 97-133.

Plotino. Enéadas (III-IV). Ed. y trad. Jesús Igal. Biblioteca clásica Gredos 88. Madrid: Gredos, 1985.

Prieto, Antonio. La poesía española del siglo XVI, vol. 2: Aquel valor que respetó el olvido. Madrid: Cátedra, 1987.

Ramajo Caño, Antonio, ed. Fray Luis de León. Poesía. Biblioteca clásica de la Real Academia Española 38. Madrid: Galaxia Gutenberg, 2006.

Reynaud, Julie. "Le rire de Marsile”. Marsilio Ficino. Métaphysique de la lumière (Opuscules 1476-1492). Eds. Julie Reynaud y Sébastien Galland. Chambéry: L'act Mem, 2008. 171-200.

Rico, Francisco. "Tradición y contexto en la poesía de Fray Luis". Academia literaria renacentista, I: Fray Luis de León. Ed. Victor García de la Concha. Salamanca: Universidad de Salamanca, 1981. 245-48.

Rico, Francisco. El pequeño mundo del hombre: varia fortuna de una idea en la cultura española. Nueva ed. cor. y aum. Barcelona: Destino, 2005. 
Rodríguez, Juan Carlos. Teoría e bistoria de la producción ideológica. 2. ${ }^{\text {a }}$ ed. Madrid: Akal, 1990.

Saitta, Giuseppe. La filosofía di Marsilio Ficino. Messina: Giuseppe Principato, 1923.

Salstad, Louise. "Sun Motifs in Sixteenth-Century Spanish Religious Poetry". Bulletin of Hispanic Studies 55.3 (1978): 211-30.

Sechi Mestica, Giuseppe. Diccionario Akal de Mitología Universal. Trads. Marie-Pierre Bouissou y Marco Virgilio García Quintela. Akal diccionarios 8. Madrid: Akal, 2007.

Soria Olmedo, Andrés. Los Dialogui d'amore de León Hebreo: aspectos literarios y culturales. Colección filológica de la Universidad de Granada 32. Granada: Universidad de Granada, 1984.

Textos Herméticos. Ed. y trad. Xavier Renau Nebot. Biblioteca clásica Gredos 268. Madrid: Gredos, 1999.

Thompson, Collin. The Poet and the Mistic: A Study of the Cántico Espiritual of San fuan de la Cruz. Oxford: Oxford UP, 1977.

Torres Salinas, Ginés. "Luz no usada y música estremada: poética neoplatónica de la luz en la oda A Francisco de Salinas, de Fray Luis de León”. Castilla: Estudios de Literatura 4 (2013): 93-136.

Torres Salinas, Ginés. “«La sacrílega envidia de Febo»: la imagen de la «dama sol» en un soneto de Fernando de Herrera". La literatura no ha existido siempre: para fuan Carlos Rodríguez. Eds. Miguel Ángel García, Ángela Olalla y Andrés Soria. Granada: Universidad de Granada, 2015.

Vasoli, Cesare. I miti e gli astri. Napoli: Guida Editori, 1977.

Vasoli, Cesare. "Su alcuni temi della «filosofia della luce» nel Rinascimento: Ficino ( $\ll$ De Sole» e «De lumine») e Patrizi (libro primo della «Panaugia»)". Annali della Facoltà di lettere e filosofia dell'Università di Cagliari (Nouva Serie) 9.46 (1988): 63-89.

Vasoli, Cesare. Quasi sit deus: studi su Marsilio Ficino. Lecce: Conte Editore, 1999.

Vicente García, Luis Miguel. "La astrología cristianizada en la poesía de Fray Luis de León”. Revista agustiniana 48.146 (2007): 307-32.

Walker, Daniel P. Spiritual \& Demonic Magic from Ficino to Campanella. Reimpr. University Park: Pennsylvania State UP, 2003.

Wind, Edgar. Los misterios paganos del Renacimiento. Trad. Javier Sánchez García Gutiérrez. Alianza Forma. Alianza Editorial: Madrid, 1998.

Ynduráin, Domingo. Aproximación a San fuan de la Cruz: las letras del verso. Madrid: Cátedra, 1990. 